\title{
Ethical Role of Buddhology in Team Learning
}

\author{
Zhenquan Lu \\ Anhui Finance \& Trade Vocational College, Anhui University of Science and Technology \\ Anhui Venture Capital Research Institute Limited \\ E-mail: lzquan365@yahoo.com.cn
}

\begin{abstract}
For human kinds to thoroughly change their developmental direction, they have to publicize another subjectivity. New development should strive for harmony of three levels: 1. ecological harmony, in which they should strive for harmonious existence with other species; 2. personal harmony, in which they should strive for peace within human community; 3. mind-set harmony, in which they should strive for harmony of sense, will and emotion in an individual's soul. The broad and profound doctrines in Buddhology's Eight Consciousness are transferred into the four wisdoms. Namely, to think comprehensively with a state of "Great Perfect Mirror Wisdom"; to surpass oneself with "Wisdom of Accomplishment"; to build a shared vision with "Wisdom of Discrimination"; to train the ethical role of team learning with "Wisdom of Equality" in ecological harmony, especially in personal harmony and mind-set harmony development, which, without doubt, has a positive leading effect.
\end{abstract}

Keywords: Buddhology culture, Team learning, Ethical role, Contemporary business ethics regression

$<<$ The Fifth Discipline $>>$ by the American Massachusetts Institute Technology Professor Peter M. Senge raised a learning revolution worldwide. Learning organization and team learning become a trend. In his research, Peter M. Senge discovered that, among the large-size companies ranked in the "Top 500" by American Fortune, one third of them had kept silent by 1980s. These abnormal phenomena aroused thinking of Peter M. Senge. Through deep study, he discovered that, it was the organization's mental retardation that obstructed learning and growth of an organization, and that finally caused failure of the organization. Mental retardation, just as the name implies, refers to obstruction in learning and thinking of an organization or a team. Peter M. Senge thought that, in order to enable an enterprise to grow up strong and sturdy, it should build a learning organization, namely, to change an enterprise into a learning organization, so as to overcome the organization's mental retardation. In the $<<$ The Fifth Discipline $>>$, Peter M. Senge pointed out that, among the five aspects of systematic thinking, self-surpass, improvement of mental models, building of a common vision, and team learning, the most important issue is to improve mental models, and attain self-surpass, on which human beings can build a common vision by means of systematically thinking. Team learning is to organize means and rules.

Primary prerequisite of learning organization is to learn to recollect. Post-modern spirit emphasizes substantiality of the internal links, advocates organicism, goes for building organic connection between humans and humans, humans and the nature, humans and the society, modernism and tradition, modernism and the future, and pursues moral value and religious value. Primacy and organism of psychic energy can be regarded as the two most fundamental features of post-modern spirit. Emphasis on psychic energy is a significant transfer of post-modern spirit about the driving force of humans' natural instinct in modern spirit. It means, at the time when the society is seeking for "the strongest motive", it is also seeking for and building "the best motive". However, the moral value and religious value of Buddhology is its concentration on psychic energy, and is the fact that team learning promotes development of the society as "the best motive".

\section{Ethical meaning of Buddhology culture}

The same as other religions, Buddhism is about the field of philosophy and culture spirit, which influences and determines humanistic disposition of a society and a nation to a certain extent. Ethics and the tradition formed by this humanistic disposition then are accumulated into a humanistic resource. The meaning of a resource lies that, human being can, thereby, acquire root motive and source, and therefore, has an extremely great developmental value. Humanistic force is a cultural nature which lies within the ethics but which is susceptible to be ignored.

Buddhism cultivates 84,000 doctrines of wisdom. However, if summarizing all doctrines, the core is to perfect one's attitude, change his disposition, his destiny and win the freedom of one's life through religious and moral practice.

Buddhology --- study of Buddhism, which should be originally named logic of Buddhism, refers to doctrines of Buddha 
power, or the truth realized by all Buddhists, namely, truth of the universe and the life. Doctrines implied in Buddhism are too broad and profound, include all studies in life (secure living, life and death) and the nomastric life (relief from life and death), and it is similar to the generally so-called "study" in itself, so it is named "Buddhology". Buddhism is indicated in the great pity and wisdom of the supreme bodhi Buddha --- Sakya, which is filled with wisdom, kindness, brightness, refreshment and comfort. Doctrine established according to this belief is Buddhism. The definition of Buddhism is "self-consciousness, consciousness of others, conduct of consciousness, which is perfect", so Buddhism is the highest standard of the personality. Briefly speaking, Buddhism is consciousness, and religion is wisdom.

The French biologist, Paris National Scientific Research Center director, and Echoldo Technique Cognitive Science and Epistemology professor Francisco. Varela has pertinent preference for Buddhism. He believes that, Buddhism is a practice, not a religion. He said, "my interest in Buddhism has impact on my viewpoint about mental wisdom. A Buddhist is an expert who understands the concept of virtual self or not-self as existence experiences at heart, which is the reason why Buddhism tradition fascinates me." In his assessment on the scientific achievements by Francisco, the Tufts University Cognitive Science Center director Daniel Dannett, who is an outstanding Literature and Natural Science professor and philosopher said, "after that, and that is the reason." He believed that, Francisco was an extremely intelligent man. And due to his broad and profound spirit, Daniel Dannett believed that his thought originated from the Buddhism.

In Chinese Buddhism Mahayana and Eight Schools, Consciousness Only approximates to science, Three-Treatise to philosophy, Hua-yen School and T'ien-t'ai School to literature, Shingon and Pure-land School to aesthetics, and Zen is the core of Buddhism. Generally speaking, Dhyana and Pureness have the greatest influences in folk, while in the academic field, Consciousness Only (Eight Consciousness) has the greatest influence.

Eight Consciousness of Consciousness Only in Buddhism includes Eye Consciousness, Ear Consciousness, Nose Consciousness, Tongue Consciousness, Body Consciousness, Wish Consciousness, Manas and Alayavijnana. The first six kinds of Consciousness are what are called "the Six Roots" in Buddhism. According to Buddhism, our Consciousness can be classified into eight kinds: Eye Consciousness, Ear Consciousness, Nose Consciousness, Tongue Consciousness, Body Consciousness, Wish Consciousness, Manas and Alayavijnana.

The "Eight Consciousness" in Buddhology plays a positive role in improving our mental models, surpassing ourselves, sincerely communicating in team learning, and improving our personality and even the economic development of the society.

Among the Eight consciousness, Eye Consciousness, Ear Consciousness, Nose Consciousness, Tongue Consciousness, Body Consciousness are called the first Five Consciousness, namely, perceptual knowledge we generally call; Wish Consciousness is the Sixth Consciousness, namely the rational knowledge we generally call. The Epistemology we learn is basically concerned with the above content. However, Consciousness Only is different, which, in addition, also involves two consciousness forms, and they are the Seventh Consciousness Manas and the Eighth Consciousness Alayavijnana. To say it briefly, these two kinds of Consciousness are actually our subconsciousness. According to Consciousness Only, the first six Consciousness forms are superficial Consciousness, and can be felt, while behind the superficial Consciousness, there exist deeper Consciousness, that is, Manas and Alayavijnana In Buddhism, the subconsciousness is the most important, because subconsciousness determines superficial consciousness, which is the realization of Alaya.

The original meaning of Alayavijnana is "storing", namely, storehouse. The general consciousness is the first six Consciousness, but the existence of the six Consciousness depends on several conditions, which is not obvious sometimes. For instance, the blind don't have Eye Consciousness. Furthermore, those who are not blind have a limited scope of eyesight, because they can't see anything when the surroundings are either too dark or too bright. The same is true in the case of all other Ear Consciousness. However, the Sixth Consciousness is relatively long-lasting. But when one is in heavy sleep without any dream, or when one is stuffy, such as in a comatose state by a staggering blow, the Sixth Consciousness does not exist any longer. Then what's the foundation for this unconscious man to survive? According to Consciousness only, man at this time does not have the superficial consciousness, but his subconsciousness exists, whose core is Alayavijnana. When one loses his consciousness, the subtle Alayavijnana still exists and activates, being an undertaker of his life.

The most significant feature of Alayavijnana is the accumulation and the state of being in effect of seeds. All our activities are stored in Alayavijnana, just like the seeds of a plant, so Alayavijnana is also called Seed Consciousness. "Seed" is a metaphor, and Buddhism is a metaphorical religion.

As a result of cognitive limitations and moral pollution, knowledge can never be perfect, and Consciousness Only puts forward the theory of "Transition from Consciousness to Wisdom" in order to thoroughly overcome this imperfectness. The so-called Wisdom is the same as its meaning in general, and it is the opposite of Consciousness. Wisdom is unlimited, and pure. It is a state which surpasses separation of subject and object, and which is called in Buddhism 
"undifferentiated Wisdom" or "Wisdom of Understanding". The end-result of Consciousness Only is to transit from the polluted and limited Consciousness into the unpolluted and unlimited Wisdom.

Specifically, transition "from Consciousness into Wisdom" means transition from Eight Consciousness into Four Wisdom. The first five Consciousness should be transferred into "Wisdom of Accomplishment", the sixth Consciousness into "Wisdom of Discrimination", Manas into "Wisdom of Equality", and Alayavijnana into "Great Perfect Mirror Wisdom". The so-called "Wisdom of Accomplishment" refers to the Wisdom which achieves the first five Consciousness. The first five Consciousness is perceptual knowledge, a specific feeling of oneself, and is limited, but after transition into Wisdom, the limitation will be eliminated. Wisdom can faithfully reflect the true colors of everything, and bring happiness to all. The so-called "Wisdom of Discrimination" refers to subtle observation on the world, whose core is co-existence of commonness and difference, namely, relation between general and individual. The Sixth Consciousness per se is rational knowledge, whose core is research on relation between general and individual. The so-called theoretical thinking is to abstract a general principle from details. Then what remains after abstraction of the whole world? There are totally different answers, based on which are formed different philosophies. For some, it is material, and for others, it is spirit. With "Wisdom of Discrimination", we can completely understand the relations between the commonness and difference in the world.

Manas is root of self-consciousness, and always advocates "existence of self", so the Wisdom after its transition is called "Wisdom of Equality", which overcomes differentiation between others and self, and observes everything with an attitude that everything is equal. Alayavijnana is a storehouse which covers all seeds of everyone, and which becomes "Great Perfect Mirror Wisdom" after transition into Wisdom. Just like an unlimited mirror, it is perfect without any defect. By the time of this state, you have already been integrated into a whole with the universe. You are everything, absolutely free, without any obstacle.

Transition from Consciousness into Wisdom is a process in which one surpasses limitation of knowledge and expands the breadth of mind until the infinity. As the old saying goes "Reading makes a full man; practicing, a competent man", which quite gets the point. Our breadth of mind should get broader, and finally get unlimited like the Sea and the Emptiness. There is a couplet at the South Heavenly Gate on Tai Mountain summit: A vast territory without immensity, bordering with the sky, and a mountain with tiptop, I being the peak. This is exactly an artistic conception from Consciousness to Wisdom. When you expand your soul to its infinity, you are yourself infinitely, which means you have accomplished the process of transition from Consciousness into Wisdom.

Then what's the ethical role of Buddhology in team learning?

\section{Ethical role of Buddhology in team learning}

\subsection{In terms of prerequisites of team learning}

Maybe we have no idea why the learning organization creator Peter M. Senge could accomplish a difficulty. In the practical chapter of $<<$ The Fifth Discipline $>>$, some scholars introduced like this "Senge practiced each discipline he advocated. For example, he attached great importance to the psychosomatic balance, and considered both his work and personal life. He was devoted to outdoor sports, and he had been in meditation for several years." Thereby, meditation is extremely helpful for one to accomplish an undertaking. Mediation means elevation of the three dimensions onto calm reflection, among which the most importance is to learn to recollect, and to attain the psychosomatic balance. However, what team learning needs is to recollect and communicate. Of course, communication should be sincere. If one achieves "Wisdom of Equality" without limitation of others and self, and obtains unconditional freedom, without any interference just like lighting, then he attains the state of Buddhism "self-consciousness, consciousness of others, conduct of consciousness, which is perfect". This is the primary humanistic foundation of team learning.

\subsection{In terms of fundamental motives of team learning}

To learn as one organization, it is the team that should vary but not an individual. The key to the success of an enterprise is no longer resource, fund, or technique, but a team and organization that can rapidly learn to meet an emergency. Potential and wisdom of each one can get fully developed. The synergy produced by wisdom and contribution of a team is far beyond the sum of all individuals. The Eight Consciousness in Consciousness Only can enlighten and help potential and wisdom of each one to be fully applied. We can imagine that, if everyone uses "Eight Consciousness" to improve his mental model and further "transition from Consciousness into Wisdom" --- transition from Eight Consciousness into Four Wisdom, thinks comprehensively with a stage of "Great Perfect Mirror Wisdom", surpasses oneself with "Wisdom of Accomplishment", builds a common vision with "Wisdom of Discrimination" and cultivates team learning with "Wisdom of Equality", then the effect and result will be quite different.

\subsection{In terms of spiritual requirements of team learning}

Team learning demands for unified emotion, belief and learning desire. Without a unified learning desire, one's heart might fly far away, and there might only be form without any effect. Then how to achieve unification? The answer is 
religion. The German philosopher Cassirer is honored as the most venerable person nowadays. He said, in some human activities and cultural forms, what we find is "unification of several functions", in which art gives us intuitionistic unification, science gives us thinking unification, and religion and myth give us emotional unification. Art opens to us a world of "living form", and science reveals to us a world of regulation and principle. Religion and myth originate from the fact that, humans realize universal existence of life and fundamental unification of culture demand for religion, and team learning too. Eight Consciousness in Buddhology is the most scientific and sapiential in Buddhology. It's said that, religion is the major part, the basis and root of spiritual life of human beings, which are exactly religious aspects of human spirit. The spirit per se manifests religion, and the so-called religious belief isn't really a particular function, but a root of all its particular functions. If not fixed, it is not likely for long-lasting and sustainable development of a root.

\subsection{In terms of ideal characteristics of team learning}

A team has a strong flexible and adaptive capacity, and can incessantly adjust, renew or alter oneself to adapt to a changing environment. An individual in a team has strong learning desire and capacity. The entire team has a profound learning atmosphere. Each one discards their original thinking way, participates in the management and gains the freedom of life. Life and work target, value and meaning of each member are integrated together and become a community of life. Of course, a learning team should also display a spiritually excellent and prosperous performance. In order to achieve this, we should cultivate the foundation of each one, namely, Alayavijnana seed and effect theory. All our activities are accumulated in Alayavijnana seeds, without exception, which is called "edified learning" in Consciousness Only. "Edified learning" is also a metaphor. The same is true for human activities, and they edify seeds ceaselessly. Exchanging ideas together is an excellent edification, because being together with so many ambitious friends can improve my Alayavijnana seed. In the process of seed edification, seeds in turn generate effects. Seeds accumulated in Alayavijnana will get into effect timely because of karma harmony, which affects our activities. Effect edifies seeds and seeds edify effect. This behavior, together thinking interaction theory, provides theoretical basis for cultivation of Buddhism and even daily moral practices.

\section{Contemporary business ethics regression}

Ethics is a study on morality, while morality is concerned with value choice, behavioral choice and personality cultivation of humans. The American Economist Francis Fukuyama conducted a deep study on relation between social morality and social prosperity through the moral norm of "trust", getting a breakthrough discovery, "the highest economic efficiency is not necessarily accomplished by a rational egoism, but by the joint effort of a group composed of by individuals. The reason is that, a common ethics among these members enables them to cooperate more efficiently." He believed that, it's not economic interests and laws that have the greatest impact on economic efficiency, but ethical morality. Although contract and self-interest mean a lot to association of group members, still an organization with the greatest efficiency is a corporation that shares a common ethical and value concept. Such a corporation doesn't need a strict contract and legal provision to standardize relations between members, for which the reason is that innate moral consensus has endowed a foundation of mutual trust among members. Trust not only improves organizational efficiency, but reduces the operating cost of an enterprise. "What kind of business economics has a society initiated is closely associated with its social capital. Supposed that all employees in an enterprise can abide by a common ethical standard, and hold a highly trusting attitude towards each other, then the operating cost of the enterprise might be relatively inexpensive. Also, such a society can innovate and develop well-regulated, because a high trust allows for a diversified social relationship."

Winner of Nobel Prize in Economics Buchanan believed that, ethics helps to resolve "great difficulties", especially able to effectively resolve opportunistic and egoistic behaviors in economic activities. William·Mommsen differentiated opportunistic behavior as prior opportunistic behavior and afterthefact opportunistic behavior. Typical manifestation of prior opportunistic behavior is retrorse choice, while afterthefact opportunistic behavior is "moral hazard". The former depends on standardization construction of the market, while the latter depends on morality construction. North, another representative man of the theory and also the winner of Nobel Prize in Economics, proposed a proposition: creation of wealth is a moral process. Arrow, the representative man of Information Economics and winner of Nobel Prize in Economics, said, "We have witnessed reactions to the balanced market failure in the norms of social behavior, including ethics behavior. Effectiveness of ethics norm has reduced extra transaction cost in economic concordat, so situation of each one has got improved."

Winner of the Nobel Prize in Economics Amartya Sen studied characteristics of economics, and he focused on significant economic issues from the moral and ethical perspectives. His contributions are summarized as follows: to call for conscience, and to focus on human predicament. In his study on economics, he tried to seek for a path of governing and benefiting the people in order to make economics return to its ethical orbit.

Throughout new development of western Economics, we can find that, integration of economics and ethics is the major trend of development of the modern market economy theory. The topic put forward by this trend is ecological recovery of the relation between ethics and economics. 
Ethical spirit of the Eight Consciousness in Buddhology displays the four "forces" indicated by the force of humanity in ethical spirit, namely, guiding force, adjusting force, standardizing force and interactive force. When the common culture-psychology structure comes into existence, it is possible that people can culturally communicate and interact. This is the ethical role of Buddhology in team learning.

Team learning is a managerial science, and Buddhology belongs to the scope of religion. The contemporary process philosopher Hui Tehai has viewed science and religion as "the two strongest powers which influence humans", and declared that, "when we think over what on earth are religion and science to human beings, it's no exaggeration to say that the process of history depends on how we handle the relationship between them." To learn a little about Eight Consciousness of Buddhology might help us further reflect over the issue of team learning, organizational training and harmonious development and construction of humans.

\section{References}

Fan, Hao. (2007). Value Ecology of Ethical Spirit. China Social Sciences Press.

John Brockman. (2003). The Third Culture, translated by Lv, Fang. Hainan Publishing House.

Master Sheng Yen. (1998). True Buddhism. Shanghai Buddhism Association.

Peter M. Senge. (1998). The Fifth Discipline, translated by Guo, Jinlong. Shanghai Joint Publishing Company.

Shang, Shuili. (2001). Team Spirit. Shi Shi Publishing House.

Wei, Zhengtong. (2005). On the New Development of Chinese Ethics. China Renmin University Press.

Wu, Guangyuan. (2003). Listen to Masters Talking about Philosophy. Civil Aviation Administration of China Press.

Zhang, Zhigang. (2002). What's the Science of Religion. Peking University Press. 